\title{
On the Issues of the Correct Vocal Tract Configuration in a Specific Voice Education Process
}

\section{Petr Špaček, Tereza Sedláčková}

\begin{abstract}
The elementary issue in a specific voice education process for future voice professionals, including students from the Pedagogic Faculty, is a subjective perception of relaxed mandible position with the correct position of the cervical spine. In a university research in 2013, the authors of the text tried to highlight the possibility of using the mentioned issue in a voice educational process in terms of pedagogical approaches. Camcorders and IT were used to eliminate the errors. The subjects tried to eliminate their errors by a self-reflection and by using a visualization of their profile positions. These problems come from their subjective perception of the vocal tract configuration during the phonation process.
\end{abstract}

Keywords: education, educator, subjectivity, research, voice.

\section{Introduction}

Voice, as a medium of communication, is used by almost every one of us. When we move our focus towards the field of specific musical education, we find out that the voice quality is a subject of greater demands. The systematic training of every adept of musical studies at the Faculty of Education helps to handle those demands and dif- 
ficulties thanks to attending the Voice Education class or its modifications which belong to the students of pedagogic faculties, especially at music departments. During their studies, it helps them to gain a dominance over the coordination process (breathing, phonation, resonance, articulation), resulting in a beautifully sounding voice in its entirety. To achieve this, you need the proper vocal tract configuration. The elementary problem in the specific voice education process is a subjective perception of the vocal tract configuration vs. objective vocal tract configuration. In the current vocal pedagogy, this issue is solved only by an educator's visual inspection or by an audio analysis when the opinions are different from the student's feelings. This is often a subjective perception of feelings which do not correspond to the real situation.

One of the major problems of the correct vocal tract configuration is the relaxed mandibular position (including the temporomandibular joint opening) along with the correct cervical spine position. The main aim of this project is to focus on the voice education effectiveness, respectively, the influence of the objectively correct mandible and cervical spine configuration. The information technologies and a camera were used to eliminate the defects. The subject tried to eliminate the defects by using a self-reflection resulting from the perception of the correct vocal tract configuration during phonation. Then, thanks to using the profile position visualisation, it was possible to confront the subjective perception with the objective (visualized) mandible position and the cervical spine. The spectrogram (a part of VoceVista-Pro) was also used for the analysis.

Advantages:

- Objectivity

- Use of hardware/software - EGG/VoceVista-Pro for getting data evaluation of voice quality parameters (spectrogram)

- Elimination of the subjective perception of the vocal tract configuration

Disadvantages:

- Psychological burden

- Small set of subjects (15)

- EGG application (putting two sensors on the outer right and left side of the larynx area)

- chosen vocal exercises (may not be optimal for everyone)

\section{The importance of voice for educators}

The vocal tract is used daily by every educator as a way to communicate. However, most of them do not realize that an integral part of using something as obvious as the human voice requires some care. The care is called "vocal hygiene" which is a prevention 
and a certain set of actions leading to a voice healthiness and the right function of the vocal tract. Maintaining or regaining the full functional voice condition is the main aim of a vocal hygiene application (Frostová, 2010, p. 70).

There is a special emphasis on the area of vocal hygiene during the educational process specialized for voice professionals and teachers (it is - according to the taxonomy established in 1979 by the Union of the European Phoneticians - the second class of voice professionals) which is a category consisting of a target group described in following lines of the project.

There is a concentration on a vocal improvement as a part of the vocal education for teachers. This improvement should be done in the field of speaking and singing voice (especially in the school program called: Music Education Focused on Voice Education). The relationship of qualitative parameters between speaking and singing voice has been demonstrated over a number of years. It is always an intentional coordination of breathing, phonation, articulation and resonation during a creation of the perfect vocal configuration, including relaxation and activities of muscles influencing each other. Harmonization of the process requires a lot of time and a highly individual approach based on the evaluation of the total trained operator's predispositions.

The Music Department of the Pedagogic faculty deals with this issue by using new study programs such as "Voice Exercises", "Speaking Voice Improving”, "Voice Re-education", "Singing Education" etc. They are focused on a systematic way of transferring theoretical knowledge to practical skills. It is systematic voice cultivation with its subsequent transfer to practice.

The greatest task was probably the one of a voice teacher because of the responsibility for future voice professionals' education, including their level of vocal expression. The main task of every educator is to analyse and prove that: "any voice should be trained for perception and for clear vision of the right stress and relax proportion by using muscles. This complicated process extends from the first auditory perceptions through a wide range of tactile perception and subsequently to visual and spatial perception, all of which are associated with the auditory experiments that are eventually reflected in an artistically meaningful sound idea with a psychosomatic creative sound feeling" (Válková \& Vyskočilová, 2007, p. 60).

\section{The effectiveness of voice training - the purpose of the project}

Streamlining of the second category professionals' voice lessons was the primary goal of the researched, financed by the Specific University Research of the Music Department belonging to the Pedagogic Faculty. For this purpose, the new interdisciplinary knowledge was used together with modern technologies in the fields of phoniatry, acoustics 
and informatics including specialised EEG equipment and the software VoceVista-Pro (Miller, 2008) for detailed analysis determining the voice issues and its transfer to the teaching area.

The project was focused on the correct application of the elementary vocal tract configuration and its impact on quality parameters in the voice production created by voice professionals during the specific voice education process by using video technologies and IT. A pilot project, carried out by Švec (2008), scanned and proved the differences between the native and opera singing expressions through the use of MRI. There is a clearly identifiable difference of the vocal tract contributions and its space. It is not caused only by the velum position and the contraction of the tongue but also by an obvious and a significant reduction of larynx - about two and a half cervical vertebras lower. For this project, it was essential to concentrate on jaw tension release including temporomandibular joint opening and moderate downshifting towards the larynx, and also to emphasise the change in the centre of a skull by a slight spine straightening in the neck area (Švec at al. 2008).

This issue was highlighted as the main issue of the whole project and there was an effort to apply this information in the educational process to eliminate the trial and error method used in education. We concentrated on the method of objectively correct pedagogical leadership, the maximum elimination of subjective feelings, which in most cases result in a poor adjustment of the mandible and cervical spine.

At the same time, these effects were assessed by a meticulous technique and based on the evaluation and analysis of the collected data with scientific information, providing a feedback of the parameters that clearly declared a systematic progress in the voice quality. It was therefore the exclusion of individual subjective opinions assessing individual voice parameters which are in some cases seen from different points of view.

The hypothesis proved that the use of new IT technologies in education for voice professionals leads to the improvement and the modernization in the field of teaching methods. The target group, including 15 students of education, specialized on - the playing an instrument - solo singing, and music culture in education, etc. Quantitative methods were used to get the results. These methods used observational, experimental and comparative approaches and a questionnaire was used as a research tool.

The whole specific education process is not based only on the relationships: educator - student, student - educator (see Figure 1). 
Figure 1

\section{voice \\ educator}

\section{subject}

(student)

Including an active students' engagement and their creative activities - singing performance (see Figure 2).

Figure 2

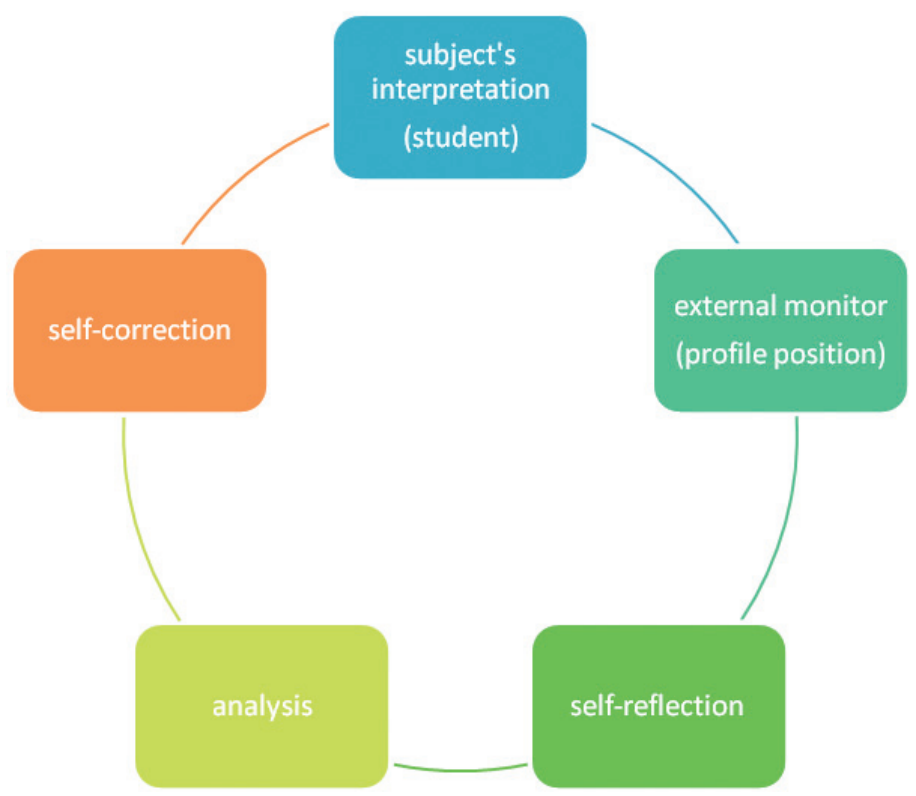

This is not a voice teacher's exclusion from the educational process but these are effectively connected polygons (see Figure 4). In this context, the great demands are put on the voice teacher and also on the audio analysis ability, observation and IT (EGG/ VoceVista-Pro understanding (see Figure 3), and evaluating of the overall voice quality parameters, as well as connections to the requirements for aesthetic parameters of the singing voice in the art. 
Figure 3

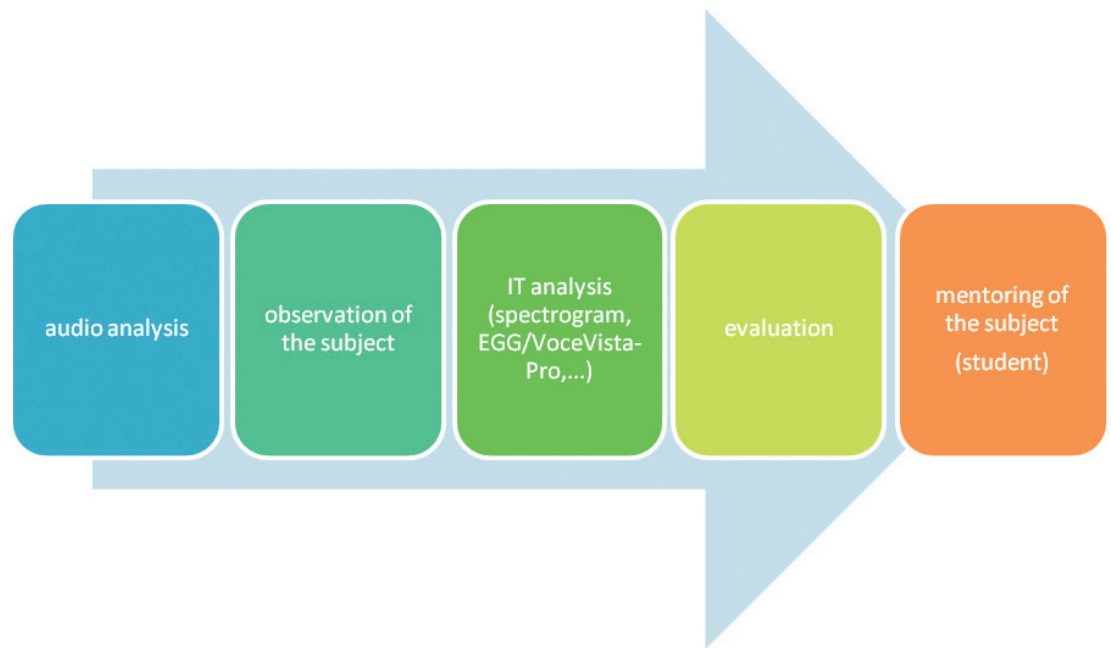

It means that the whole process has this form (see Figure 4).

\section{Figure 4}

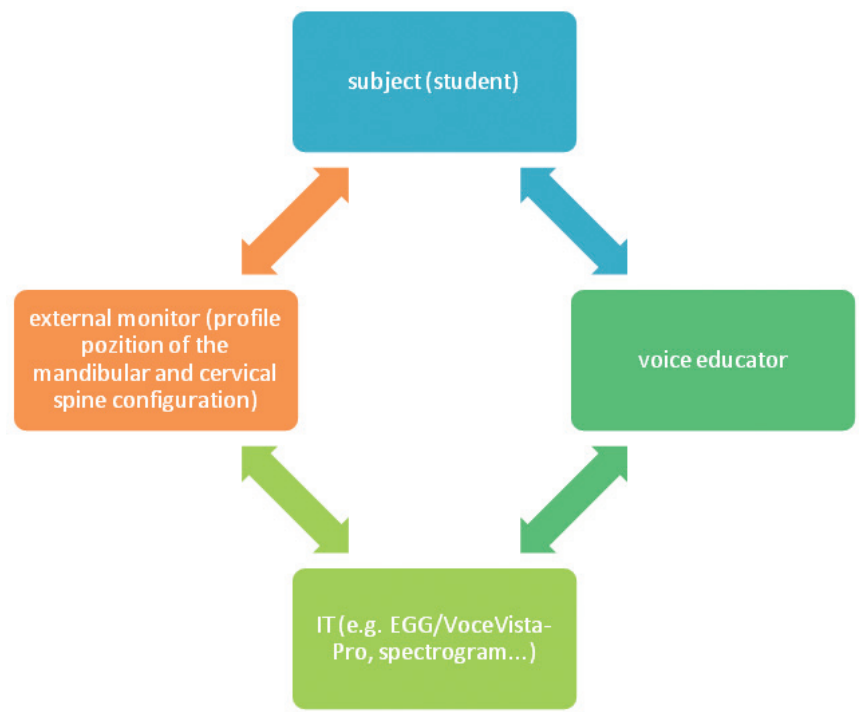


At the same time, these effects were assessed by a meticulous technique and based on the evaluation and analysis of the collected data with scientific information, providing a feedback of the parameters that clearly declared a systematic progress in the voice quality. It was therefore the exclusion of individual subjective opinions assessing individual voice parameters which are in some cases seen from different points of view.

\subsection{A brief description of the project}

Quantitative methods were used to get the results. These methods used observational, experimental and comparative approaches and there was a questionnaire as a research tool.

The tested group consisted of 15 subjects. These are the students of the Music Department, Pdf UHK. Seven of them completed a training of the Music School Conservatory and now they continue to study solo singing at the university. One of them graduated from the master's degree in another field of study. The others are graduates of a general secondary education (high schools, secondary pedagogical schools) with a voice education at the School of Music. The average duration of the vocal education is 11.4 years. The average age is 24.5 years. Each subject was given 30 minutes to the voice production. During this time, we expected a progress in the voice quality parameters.

\section{The main aims of the project:}

- elimination of errors caused by the subjective perception of the "correct" position and the ratio of tension and relaxation in the mandible and cervical spine

- objectification of the educational process by using AV, specific hardware and software in voice education

- self-qualitative parameters (spectrogram) in the interpretation of simple vocal exercises for voice professionals in real time

- effectiveness of the new teaching approaches in voice education

First, the subject filled the questionnaire No. 1 (pre-test) and subsequently interpreted the voice exercises No. 1. Data was collected via EGG, VV-P and recorded by camcorders. Everything was archived. Then the subject was shown the recorded performance with an explanation about the neck and back muscles' influence on the vocal tract configuration needed for the right singer's formant tuning (Švec at al. 2008, also MCcoy 2012).

Then the subject interpreted the same exercise which was visualized on an external monitor in real time. It was important both for the subject (because of a subject scanning from the profile angle - mandibular) and for the observer using the sw VoceVistaPro. The subject's response was evaluated and recorded. Everything was based on the changes of the vocal tract configuration and on the analysis using a spectrogram (a part of VoceVista-Pro). In this manner, the sample was applied in several exercises. In 
conclusion, the subject completed a questionnaire No. 2 (post-test). The comparison of data and recordings was statistically evaluated including the progress in subject's voice quality parameters.

\section{Results}

The project points to the use of the self-reflection and self-correction seen from the profile angle (camcorder was recording the subject's profile and it was visualized on an external monitor in real time). The result could be assessed objectively and measured via spectrogram, on which the subject is able to react in an almost real time. (MCCOY, S. 2012).

\subsection{Spectrogram}

As an example of the spectrogram use, there is a slide no. 1, where we can compare the qualitative parameters of one of the fifteen observed subjects. The B flat major scale was sung on the vocal "a". Below the picture: you can see the singing without using a proper neck spine configuration including the position of the mandible. Above: we can see the influence of the correct positioning in the cervical area by using a self-correction, or the use of correct singing posture, including the lower jaw and its influence on the singing tone.

There is highlighted $2 \mathrm{kHz}$ band $-3.5 \mathrm{kHz}$ in the particular area. It is a range of frequency where the strong resonance is situated. This frequency and its timbre are typical for opera singers (Švec, 2006). The comparison proves the ability of profile capturing to be helpful in the subject's education for the future voice professionals. In the picture no. 1 we can observe the intensification of the rich resonant frequency which is typical for opera singers. We can see it as a rich spectrum of harmonic tones. 


\section{Picture 1}

Above: with the use of video and IT;

Below: without the use of video and IT.

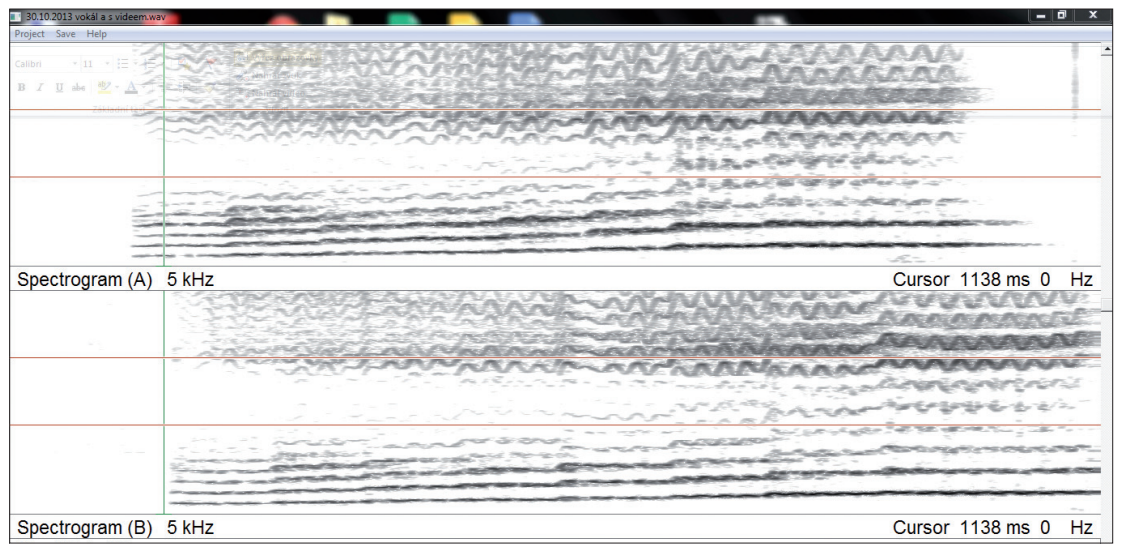

In the spectrogram, twelve of the fifteen examined subjects profiled the increased number of the harmonic tones. Three subjects would probably feel the change in a longer period of time. It should be noted that all three students have not completed a solo singing at the conservatory. The success within a richer spectrum of overtones, due to the self-correction profile using the visualization, is $80 \%$ with a 30 minute time allocation.

\subsection{Questionnaire survey}

Use of this innovative method could support the view of subjects whose average length of education in voice education is 11.4 years. The research instrument was a questionnaire consisting of a pre-test and a self-evaluation post-test assessing the qualitative progress of the production and the innovative approach using IT. Total $100 \%$ of respondents answered that they were satisfied with the innovative teaching method and the same number answered the question about the benefits of the profile angle visualization.

There is an interesting discrepancy in opinions evaluating the effectiveness of the clarified issue. $100 \%$ of respondents understand the topic more quickly, but only $80 \%$ of them would use this method in a future training; $100 \%$ of respondents are convinced of the impact on singing voice due to the mandible and cervical spine position. It is remarkable that during the innovative method $100 \%$ of respondents felt change in the 
location of the cervical spine position. Positive contributions within the vocal education were perceived by $87 \%$ of them.

There can be seen the importance of using the objectification in the music education, when $53 \%$ of respondents perceived the opinion different from the educator's one.

\section{Chart 1}

\section{An Extract from the Questionnaire}

- Have you ever had any voice problems (have you ever been treated by a phoniatrist)?

- Have you ever considered your voice teacher's assessment as his or her subjective opinion you disagree with?

- Have you ever worked with a mirror as a self-reflection aid?

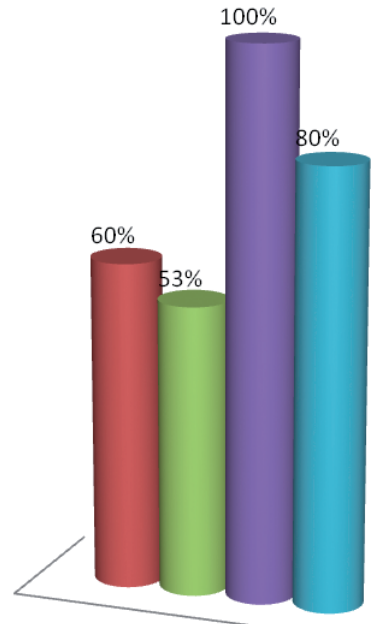

1

\section{An Extract from the Questionnaire}

Do you think that the cervical spine configuration has an influence on your singing performance

- Do you think that there were some qualitative changes in your production?

- Did you feel any change in the vocal tract configuration in the area of the cervical spine?

- Would you like to be taught by this kind of education even in the future?

- Did you feel a faster way of understanding the give issue?

- How much were you satisfied with the innovative way of teaching - using IT?

- Did you find any benefit when seeing yourself from the profile angle?

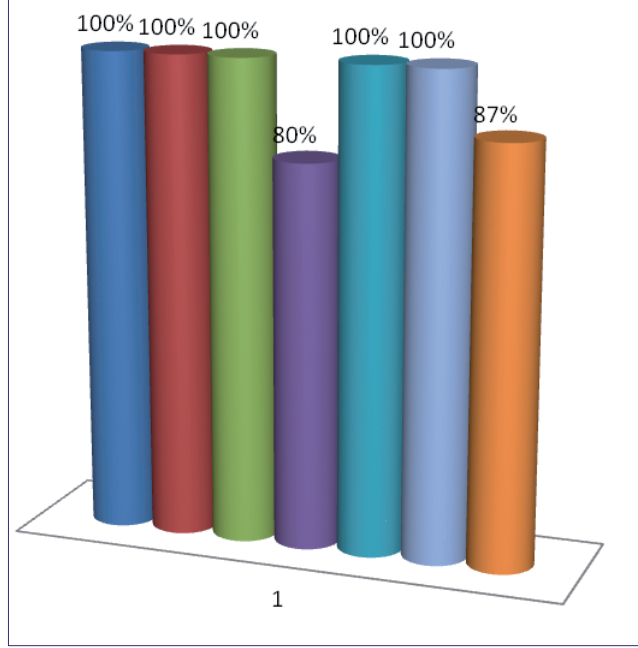




\section{Conclusion}

After analysing the collected data and information, it is possible to give learners the objective information about their qualitative parameters of voice production (by the visualization $=$ the spectrogram) with a certain evaluation and a possibility to respond to them as well.

The expected elimination of the particular mistakes originating from a subjective perception of voice quality and the development in objective acceptance of qualitative parameters in voice production has turned out according to the mentioned results, and thus we may state that this current pilot project has been favourably accepted by the targeted group.

Thanks to this innovation the whole process of systematic education in this specific field of voice training can be more efficient. The described manner which uses the modern equipment, including IT in singing education, could lead to the optimization and modernization of methods not only in singing and voice problems, but also in the field of rehabilitation and voice re-education for voice professionals.

Finally, it is necessary to add a fact that this kind of education cannot replace the teacher's role in any way. A teacher's professional approach and excellent audio-analysing ability is irreplaceable! The respect to the voice teacher's role is described in a statement of a Czech phoniatrist O. Lacina: "An experienced and professional ear of an attentive listener to a melodically voice, professional singer or music teacher has not only the ability to distinguish gentle nuances in the methods of voice origin but also is capable to evaluate displays and traces of higher nervous activity within the voice and variable stages of emotions and mental statuses like feelings, moods, excitement, etc." (Lacina, 1977, 102; well as Frost, 2010, 87).

\section{References}

Frostová, J. (2010). Škola a zdraví pro 21. století, 2010: péče o hlasovou kondici učitelů. Brno: Masarykova univerzita ve spolupráci s MSD.

Lacina, O. (1976). Problémy zpěvního hlasu. Praha: Panton.

McCoy, S. (2012). Your Voice: An Inside View. $2^{\text {nd }}$ ed. Delaware, Ohio: Inside View Press.

Miller, D. G. (2008). Resonance in Singing: Voice Building through Acoustic Feedback. Princeton, NJ: Inside View Press.

Švec, J. (2006). Tajemství hlasu: 4. přednáška z cyklu Vědeckopopulárních přednášek významných absolventů Univerzity Palackého v Olomouci pořádaných za podpory statutárního města Olomouce: Olomouc, 25. dubna 2006. Olomouc: UP

Švec, J., Herbst, C., Havlík, R., Horáček, J., Krupa, P., Lejska, M., Miller, D. G. (2008). Singer's Formant: Preliminary Results of MRI and Acoustic Evaluations of Singers. In Proceedings Interaction and Feedbacks 2008, edited by I. Zolotarev, Prague: Institute of Thermomechanics AS ČR.

Válková, L. \& Vyskočilová, E. (2007). Hlas individuality. Praha: Akademie múzických umění. 


\section{Research, project}

Specific Research 2013, number of the contract: 2132

„Využití EGG k reflexi kvalitativních parametrů u zpěvního hlasu. Kobjektivizaci pěveckého edukačního procesu."

\section{Contact:}

MgA. Petr Špaček, Ph.D.

Univerzita Hradec Králové, Pedagogická fakulta

Rokitanského 62, 50003 Hradec Králové

E-mail: petr.spacek.2@uhk.cz

Bc. Tereza Sedláčková, DiS.

Univerzita Hradec Králové, Pedagogická fakulta

Rokitanského 62, 50003 Hradec Králové

Tel.: (+420) 495063128

E-mail: tereza.sedlackova@uhk.cz 